\title{
Erratum to: Bone-Targeted Therapies for Elderly Patients with Renal Cell Carcinoma: Current and Future Directions
}

Thomas Roza • Lukman Hakim •

Hendrik van Poppel · Steven Joniau

Published online: 13 November 2013

(C) Springer International Publishing Switzerland 2013

Erratum to: Drugs Aging (2013) 30:877-886

DOI 10.1007/s40266-013-0117-5

Pages 879-880: Corrections to reference numbers in Table 1 sections (a) and (b):

Stopeck [63] should read Stopeck [67]

Henry [65] should read Henry [69]

Fizazi [64] should read Fizazi [68]

Lipton [66] should read Lipton [70]

Smith [67] should read Smith [71]

Beuselinck [78] should read Beuselinck [82]

Keizman [79] should read Keizman [83].

The online version of the original article can be found under doi:10.1007/s40266-013-0117-5.

T. Roza $(\bowtie) \cdot$ L. Hakim · H. van Poppel · S. Joniau

Department of Urology, University Hospitals Leuven, Herestraat 49, 3000 Leuven, Belgium

e-mail: Tomroza@hotmail.com 